\title{
Executive Guidelines for Evaluating Consultants
}

\author{
Ralph Gallay ${ }^{1}$ \\ ${ }^{1}$ College of Business Administration, Rider University, Lawrenceville, New Jersey, USA \\ Correspondence: Dr. Ralph Gallay, Rider University, 2083 Lawrenceville Road, Lawrenceville, New Jersey, 08648, \\ USA. Tel: 609-895-5546. E-mail: gallay@rider.edu
}

Received: August 14, 2013

Accepted: September 2, $2013 \quad$ Online Published: November 7, 2013

doi:10.5430/ijba.v4n6p1

URL: http://dx.doi.org/10.5430/ijba.v4n6p1

\begin{abstract}
This research investigates issues regarding the evaluation of corporate and institutional consultants. There is considerable information to assist those who conduct research, but little to facilitate the evaluation of others who perform it. This study integrates ideas found in the literature with those of the researcher who has been a consultant and a client, together with empirically generated executive input. The author conducts a series of personal interviews with corporate and institutional individuals on the client-consultant interface. The information comes from publicly-held and privately-owned organizations in both profit and not-for-profit sectors. The findings lead to an improved understanding of how consulting efficiencies can be enhanced.
\end{abstract}

Keywords: evaluating a consultant, managing a consultant, part-time employee

\section{Introduction}

\subsection{Goals and Significance of the Project}

The goal of this project is to expand the scholarly literature on the client-consultant relationship by focusing on guidelines that are used to select and evaluate consultants across different industries among publicly-held and privately-owned organizations in both profit and not-for-profit sectors. This particular paper pertains to the evaluation process alone. Much of the literature on this subject at the time of this research is somewhat dated or is anecdotal in its treatment of the subject, written mainly as non-scholarly short articles of interest in trade magazines. This study is designed as a literature-based, empirical, descriptive research inquiry.

It is to be noted that this is the second part of a previously published study by this author entitled Executive Guidelines for Selecting Consultants (Gallay, 2013), Some sections of this current paper therefore by necessity, are similar to those published previously dealing with the selection of consultants, but the focus of this new full manuscript is on the evaluation process. For instance, the abstracts are similar as are the goals of the project, its direction, the methodology, and tables describing those interviewed for the study. However, those similarly occurring sections are presented here in this paper in their entirety so as to give this work a stand-alone quality that will enhance its readership and understanding. The main and important differences that remain between the two papers focus on the literature or many avenues of inquiry, the findings and discussion, and the conclusions.

This paper was presented in abstract form under the title of How Executives Evaluate Consultants at the World Academy of Researchers, Educators and Scholars in Business, Social Sciences, Humanities and Education (WARES) in Cape Town, South Africa (Gallay, 2013).

\subsection{Project Direction}

Most texts on the subject of research methodology focus on design and implementation. There is a scarcity of published information pertaining to the evaluation of consultants who perform research on behalf of a client. Few companies have the staff with both the qualifications and time to manage critical unstructured requirements (Messmer, 1999). In such cases consultants are needed, especially when projects are of limited duration, require intense time commitments, or require otherwise unavailable specialized skill (Ibid.). As a result approximately eighty-five percent of executives are reported to believe that consultants are necessary for their business and in fact, have used them (Cohen, 1999).

It is the objective of this study to develop more current and relevant guidelines by which consultants can be evaluated. This inquiry crosses diverse fields of consulting activity. Both corporate and institutional organizations 
have been considered, as well as a range of activities among industry sectors within those areas. Additionally, profit and not-for-profit centers have been included. Even professional practices and family businesses are prime candidates for consulting engagements (Dennis, 1999). The objective is to develop sufficiently new and important knowledge on the subject.

\section{Literature Review}

At the time of this study, a review of the relevant literature on the subject of the client-consultant relationship revealed mostly anecdotal findings. It appeared clear that this was a subject worthy of a more formal, scholarly inquiry. As stated, methodology herein consisted of a series of executive depth interviews with corporate and institutional individuals who interface with consultants. Twenty interviews were conducted. Through these sessions, sufficient information was gathered to develop meaningful and informative findings. Several avenues of inquiry emerged from the relevant literature. These issues form the basis of this project's investigations and are set out in the following sections.

\subsection{Chemistry and Intangible Issues}

How does the client judge the interaction or "chemistry" with a prospective consultant? Several individuals have had a comment to make about this area. Meyers \& Lubliner (1998) advocate that the client and primary consultants should meet before any decision is made, recognizing that the individuals who work together must get along with each other. Roberts (1999) feels it is necessary to evaluate a consultant's intangible qualities such as critical thinking, as well as the ability to classify, organize and recognize patterns. And finally, Barnett (1999) feels consultants must have a willingness and ability to tailor their skills to the company's needs working for the best possible fit between the two. Often these can only be assessed through a personal meeting and defined by what may be classified as "chemistry".

\subsection{Evaluating the Proposal}

Is a written proposal required of the consultant and if so, how is it evaluated? "A consultant needs to prove that he knows a company's culture, understands its business, and cares to improve its revenues" (Cohen, 1999). One would think that this is best done through a written proposal. In fact Meyers \& Lubliner (1998) advocate a written proposal be submitted prior to the start of work, outlining procedure, methodology, demonstrated understanding of the assignment, the work, fees and time requirements. More simply, Everett (1997) asks whether the proposal states why the research is being conducted and how if at all, clients give feedback to consultants with regard to their proposals.

\subsection{Evaluating the Final Report}

With regard to the written reports submitted by the consultant, some feel that researchers are concerned that no one is reading them (Everett, 1997), so perhaps there is some general misunderstanding between the parties on this issue. The question arises as to how a final report or finished project is evaluated and whether it has something to do with its manner of presentation or the outcome of the project. Another concern is to what degree the client is sufficiently trained or knowledgeable in the subject matter of the consultant's inquiry in order to pass judgment on the proposed or submitted work. There are other incidental issues to consider that might bear on this evaluation process, such as whether the consultant will have a title, who will work with him/her, who will supervise him/her (Messmer, 1999).

\subsection{Evaluating the Consultant}

To what extent do companies or institutions accept the advice of consultants at face value, in comparison to a more critical scrutiny of advice offered by employees? Some feel that outsiders who are less subject to internal management pressure are able to offer more objective and valuable advice when it comes to strategically complex issues (Meyers \& Lubliner, 1998). Others too, suspect that outsiders get listened to more than insiders (Dennis, 1999). Client evaluation of the work of a consultant as it progresses is an issue. The process might follow a critical, objective, formal review, or it could be more subjective and haphazard. Information from a consultant might consist of misinformation as well as harmful information, when what is needed is good information (Semon, 1997). So far, according to him, the problem of assessing the quality of information has not been solved. Sometimes, it appears that the perceived quality of a specific item, such as a survey sample can significantly affect the evaluation of overall research quality (Lee, Lindquist and Acito, 1997). In any event, feedback from both employees and managers on the consultant as well as the research is important (Messmer, 1999).

\subsection{Implementing the Consultant's Advice}

One suggestion is that clients expect consultants to guide them through specifics, in fact teaching them (Anonymous, 1999). On the other hand Roberts (1999) suggests that reasonably intelligent people within the company, with certain 
characteristics, aptitudes and motivation can be trained to do the job of a consultant in which case they are not only able to pass judgment on others' work, but perhaps can render them unnecessary. Is the consultant expected to demonstrate how findings relate to company strategy and tactics and who makes the decisions on implementing the research findings, the client or the consultant (Everett, 1997)? Many managers feel the research is not delivering the kind of information they need to make proper decisions (Ibid.) when perhaps there is a lack of understanding on how to carry out the consultant's suggestions. Messmer (1999) suggests that the consultant stay with the project through the implementation stage to its successful completion by the client. Dennis (1999) also found that indeed, successful consultants do help their clients work through the action plan rather than just letting them try it on their own.

\subsection{Follow-up Relationship with Consultants}

What specific guarantees are required of the consultant with respect to time and budgetary constraints? Meyers \& Lubliner (1998) feel cost allocations for research should be divided into a number of slices, each representing a portion of the consultant's inquiry. That could give the client greater control and flexibility with respect to paying for work completed, or terminating both work and expenses at any phase. Clients or the consultants might be expected to conduct a follow-up evaluation of a consultant's advice to determine how well it was suited to and predicted the outcome of the situation for which it was intended. Companies must hold consultants responsible, making them prove their worth (Cohen, 1999). This in large part can only be done after the fact. Both clients and consultants he feels, must not only define the project's goals, but it is the consultant especially that must follow up to ensure that the initiatives are working (Ibid.). Many companies must not be doing this since Cohen reports about fifty percent are either not satisfied, or only somewhat satisfied with the consultant's work.

These are some of the questions and issues pertaining to the evaluation of consultants that have been pursued during the executive interviews.

\section{Methodology}

\subsection{The Nature of the Design}

The nature of this methodological design was descriptive, yet the investigation had to be open-ended and sufficiently flexible to permit not only these, but other possible avenues of inquiry. Twenty executive depth interviews, each lasting one to two hours, were completed and this in itself was impressive that in all cases, all individuals including top executives at the level of Vice President or even President granted the researcher such exclusive access. Additionally, in every single case respondents allowed the entire interview to be recorded so that it could later be transcribed personally by the researcher, yielding over one hundred and fifty (150) pages of written notes for analysis. For a profile of the types of companies included in this survey see Table 1.

Table 1. Profile of those interviewed

Industry/Service Sectors Represented

Government (Municipal, State)

Research \& Development (Bio-Technology/Pharmaceuticals, Marketing, Scientific)

Media (Internet, Print, Radio, Television)

Education (K-12, University)

Publishing (Business, Financial, News)

Restaurant (Management)

Health-Care (Home Health, Hospital, In-Patient/Out-Patient Mental Health Services, Long-Term Care \& Rehabilitation)

Manufacturing/Marketing (Agricultural Products, Airline Equipment, Chemicals,

Consumer Products, Energy Systems, Food Machinery, Health-Care Products,

Medical Devices, Nutritionals, Pharmaceuticals)

\subsection{The Sample}

The individuals selected for participation came from a broad range of ten publicly held, six privately owned companies and four institutions, fifteen from the for-profit and five from the not-for-profit sectors. Amongst them they employed the services of over two hundred and fifty (250) types of consultants filling a myriad of applications. All but two were located in New Jersey, USA a regional center of major business activity within the country. Certainly many more organizations might have been contacted and in neighboring states, but since only twenty (20) 
executive interviews were conducted there were more than enough from which to choose in the immediate area. Besides, getting the cooperation from the executives that chose to participate was not an easy task. Considerable planning, searching and convincing had to be done just to line up the twenty that were interviewed. For a complete list of participating companies see Table 2 .

Table 2. Executive interview participants

\begin{tabular}{|c|c|}
\hline Title, Company and Location & Nature of the Business \\
\hline 1. Township Administrator & Non-Profit, \\
\hline Township of Plainsboro, Plainsboro, N.J. & Municipal Government \\
\hline 2. Staffing Consultant, Contingent Workforce & For Profit, Privately Owned, \\
\hline Sarnoff Corporation, Princeton, N.J. & Scientific Research \\
\hline 3. Chief Administrative Officer & For Profit, Publicly Owned, \\
\hline Total Research Corporation, Princeton, N.J. & Marketing Research \\
\hline 4. Assistant Controller & For Profit, Publicly Owned, \\
\hline ABC Television Network, New York, N.Y. & Television Network \\
\hline \multicolumn{2}{|l|}{ 5. Assistant Superintendent } \\
\hline Finance and Support Services & Non-Profit, \\
\hline West Windsor-Plainsboro School District & Public Education, (K-12) \\
\hline \multicolumn{2}{|l|}{ Princeton Junction, N.J. } \\
\hline 6. Editor-in-Chief, Books and Magazines & For Profit, Privately Owned, \\
\hline Bloomberg Publications, Princeton, N.J. & Publishing \& Media Services \\
\hline 7. Director of Creative Services & For Profit, Privately Owned, \\
\hline Bloomberg Publications, Princeton, N.J. & Publishing \& Media Services \\
\hline 8. Director of Human Resources & For Profit, Publicly Owned, \\
\hline Global Business Services & Diversified Manufacturing/Marketing \\
\hline \multicolumn{2}{|l|}{ Bristol Myers Squibb Co., Princeton, N.J. } \\
\hline 9. Vice President & For Profit, Publicly Owned, \\
\hline Biostatistics, Clinical/Regulatory Operations & Fully Integrated Bio-Technology \\
\hline The Liposome Company Inc., Princeton, N.J. & and Pharmaceuticals R\&D \\
\hline 10. Vice President, People and Communications & For Profit, Privately Owned, \\
\hline Sarnoff Corporation, Princeton, N.J. & Scientific Research \\
\hline 11. President, Chief Executive Officer & For Profit, Privately Owned, \\
\hline The Rose Group, Newtown, PA. & Restaurant Management \\
\hline 12. Manager Central Support & For Profit, Publicly Owned, \\
\hline Network and Computer Services & Publishing \\
\hline Dow Jones \& Company, Princeton, N.J. & \\
\hline \multicolumn{2}{|l|}{ 13. Human Relations Manager } \\
\hline Agricultural Products Group R\&D & For Profit, Publicly Owned, \\
\hline $\begin{array}{l}\text { FMC Corporation, Chemical R\&D Center } \\
\text { Princeton, N.J. }\end{array}$ & Manufacturing/Chemical Research \& Development \\
\hline 14. Director, Financial Services & For Profit, Publicly Owned, \\
\hline Dow Jones \& Company, Princeton, N.J. & Publishing \\
\hline 15. Vice President & For Profit, Publicly Owned, World's Largest \\
\hline $\begin{array}{l}\text { Corporate Business Development } \\
\text { Johnson \& Johnson, New Brunswick, N.J. }\end{array}$ & Manufacturer and Marketer of Health Care Products \\
\hline
\end{tabular}


16. Corporate Treasurer

Johnson \& Johnson, New Brunswick, N.J.

17. Vice President of Tax

Covance Inc., Princeton, N.J.

18. Vice President, Finance

The Medical Center at Princeton

Princeton, N.J.

19. Assistant Director

New Jersey, Department of the Treasury

Division of Purchase \& Property

Trenton, N.J.

20. Vice President for Finance and Administration

Princeton University, Princeton, N.J.
For Profit, Publicly Owned, World's Largest

Manufacturer and Marketer of Health Care Products

For Profit, Publicly Owned,

Contract Drug Research Development Services

Non-Profit, Community Based/Community Directed

Institutional Facility, Health Care Medical Center

Non-Profit,

State Government

Non-Profit, Privately Owned,

Higher Education and Research

\subsection{The Framework for Analysis}

The interviews were all conducted personally by the author on a face-to-face basis, typically in each executive's office using a survey instrument consisting of approximately seventy (70) questions, each formed to explore specific issues gleaned from the literature and discussed in the previous section. Coding and analysis of the responses followed standard acceptable procedures for such open-ended data. Because of the limited sample size and the open-ended nature of this inquiry, data were not subjected to statistical significance tests, but were analyzed and are presented in a qualitative framework, addressing each of the issues outlined in the literature discussion. Results therefore are purposely expressed in descriptive terms such as most, a majority, etc., rather than by quantitative measures.

\subsection{The Timeframe of the Data Collection and Literature Search}

It is to be noted that all of these interviews were conducted in the summer of 2000 . The data were never analyzed until much later. Still, the interviews being that they were with corporate executives have a lasting timeliness to them and offer a valuable insight even now. As such, the study serves as an important investigation into the scholarly issues and managerial attitudes surrounding this topic as of the turn of the century and the beginning of the current millennium. This research therefore, can serve as a benchmark for future archival and comparative studies on the same subject. Certainly more recent literature on this subject has since been published, but that would be the basis of an update, or a second follow-up study to this one. Only the literature sources actually used in this study appear in the reference section.

\section{Findings and Discussion}

\subsection{Focus of This Study}

It was initially explained that the goal of this project was to expand the scholarly literature on the client-consultant relationship by focusing on guidelines that are used to both select and evaluate consultants across different industries among publicly-held and privately-owned organizations in both profit and not-for-profit sectors. It was also emphasized that this particular paper pertains to the evaluation process alone. As to findings related to the selection of consultants these were investigated and discussed along the following guidelines: search process, criteria sought, selecting the consultant, status of the consultant, qualifications of the consultant, credibility of the consultant and contractual issues (Gallay, 2013).

\subsection{Qualifying Questions}

Respondents were asked a few qualifying questions to insure the appropriateness of including them in the survey. These included the following issues. All respondents indicated their organization or institution used consultants. The individuals interviewed all had a role in selecting and/or evaluating consultants. Most were involved with the preparation of the contracts specifying legal and consulting terms. Many were the actual supervisors or managers of the prospective consultants. Some networked with other firms or departments within their own company to engage the services of consultants. The range of consulting specialties most sought after, varied considerably. Those mentioned most often included technical designers as well as marketing, advertising, financial, information technology and other general services. 


\subsection{Chemistry and Intangible Issues}

When asked how one judged or placed a value on the interaction "chemistry" with a consultant, the responses were varied, mostly relating to a compatibility feeling between the consultant and the client team, the communication between them and the outcome of the project in terms of its success. Prior to a consultant being engaged, in a large majority of cases, individuals who were to work with the consultant met and provided an assessment of the degree to which they thought they would get along well. In almost all cases clients attempted to evaluate a consultant's intangible qualities such as critical thinking, ability to "think outside the box", as well as the ability to classify, organize and recognize general patterns. Clients seemed willing to select a consultant to whose expertise the client would be expected to adapt, as long as it was a mutual effort of compromise. In a lesser but fairly large number of cases, clients expected the consultant to adapt his/her skills to meet the requirements of the company.

\subsection{Evaluating the Proposal}

Almost all clients required a written proposal from a prospective consultant, but on occasion, not. If a written proposal was required, besides goals and approach to the problem, the proposals had to specifically outline time requirements, cost expectations and the experience of the consultant. In evaluating a proposal both absolutely and in terms of ranking it against others or an ideal, a few clients used a matrix-grading approach, some placed emphasis on the verbal interview, more evaluated the quality of their informal discussion, but most it seemed focused on the descriptions therein of time requirements, cost expectations, proposal goals and prior experience. As to whether clients ever gave feedback to consultants who were not selected, most it appeared did so, but only if asked for it. An almost equal number did it on a regular basis. Only few it appeared were evasive on this issue or did nothing in this regard and sometimes because they were fearful of discrimination charges.

\subsection{Evaluating the Final Report}

Rarely would consultants have a specific title while engaged with the client so this had no influence on their image in the evaluation process. Clients seemed generally to feel that consultants were not concerned that their reports were not being read, but for an equal number this seemed often or always to be an important concern. In evaluating a consultant's final report or finished project, most placed greatest emphasis on whether the outcome had been successful, but some placed importance on the consultant's frequency of interaction with the client, or formal written and verbal presentation. Some few it seemed did not go through this formal evaluation of a final report or finished project. Generally, without elaboration most clients felt their own managers had the appropriate training or subject knowledge in order to pass judgment on the consultant's report or submitted work.

\subsection{Evaluating the Consultant}

When it came to accepting a consultant's advice at face value, or rather being more critical and scrutinizing more carefully in comparison to an employee, in an almost equal number of cases it appeared that consultants were either evaluated differently with higher standards, or alternatively would be treated the same as employees. Most felt that outside consultants could give more objective and valuable advice than insiders when it came to strategically or tactically complex issues, but not always and in some cases it depended on the project. As to the work of a consultant as it was progressing, most were evaluated on a continuous basis occurring in meetings between the two entities. Some monitored whether time-lines and milestones had been met and others waited for the final report. While some characterized the review of a consultant's work as being subjective and haphazard, in the large majority of cases it was considered to be objective and formal. There was almost no response when clients were asked how they assessed the quality of information, or work that the consultant provided to be sure it was helpful rather than harmful, nor any consideration if it was ultimately harmful, as to who would be responsible. In passing judgment on the consultant's work, in most cases this was done by looking at both specific details as well as making an overall assessment, but some few focused in on one characteristic alone. When assessing the quality of a consultant's work, rather than rely on the consultant's report alone, almost all clients tried to get feedback from many other employees and managers.

\subsection{Implementing the Consultant's Advice}

Most clients expected their consultants to guide them through their specific recommendations, in fact teaching as they went. Some few did not. In very many instances but not all, clients tried to train individuals within the firm to learn from the consultant, in fact taking over their role, rendering the consultants unnecessary. It depended on the project in some instances, but in most cases the client expected the consultant to demonstrate how his/her findings related to their firm's strategy and tactics. When it came to implementing the findings, in most cases the client manager, the project team, or anyone affected made this decision, even shareholders, but not the consultant. When asked how comfortable they were that consultants delivered the kind of information needed to make proper decisions, 
almost all replied that they were very comfortable with that thought. More often than not, it appeared that clients felt a consultant's suggestions were good, but were not clear on how to implement them. In most instances it seemed to depend on the situation as to whether the consultant should stay with the project after the report was submitted, on through the implementation stage to its successful completion by the client. Again while it depended on the agreement, most clients it seemed considered the consulting experience to be more successful if the consultant helped in the implementation of their suggestions, rather than just leaving the client on their own at that stage.

\subsection{Follow-up Relationship with Consultants}

While this was an important item in the selection process, it appeared very few clients required guarantees from a consultant with respect to conforming to cost and time constraints and none indicated that any steps were taken if these requirements were not met. In most instances payment for a consultant's services was made in installments over a number of stages of the project, but not always, some being paid at the end. Most clients responded that on occasion, they had terminated a consultant's services prior to completion of the work, but some had never done so. In most cases clients conducted a follow-up evaluation of the consultant's advice to see how well it was suited to and predicted the outcome of the situation for which it was intended, but in a large number of cases this was not done. In almost all cases, the consultant was held responsible or liable, either legally, morally, or ethically for his/her recommendations, in fact making them take ownership in their work with the attitude that they must provide satisfactory results, or prove their worth even after the work was completed, although some clients indicated this was difficult to accomplish. Most consultants followed up on their own after the fact to insure their initiatives were working. When asked, all respondents indicated they were either generally or very satisfied with the use of consultants by their organizations.

\section{Conclusions}

\subsection{Overall}

This research has investigated many questions that have been raised in the literature as being meaningful and important in the evaluation of consultants. Results have been categorized along six main dimensions. Although the approach was qualitative and based on a rather limited but highly selective series of open-ended executive depth interviews, the findings are extremely rewarding. The fact that twenty corporate and institutional executives, many at very high levels, shared their views which are reported here made for a unique insight to their thinking and decision-making.

\subsection{Specific Guidelines for Evaluating Consultants}

The findings yielded the following guidelines used in a majority of instances by executives evaluating consultants:

- "Chemistry" with a consultant mostly related to a compatibility feeling between the consultant and the client team, the communication between them and the outcome of the project in terms of its success.

- In a large majority of cases, individuals who were to work with the consultant met and provided an assessment of the degree to which they thought they would get along.

- In almost all cases, clients attempted to evaluate a consultant's intangible qualities such as critical thinking, ability to "think outside the box", as well as the ability to classify, organize and recognize general patterns.

- Clients seemed willing to select a consultant to whose expertise the client would be expected to adapt, as long as it was a mutual effort of compromise.

- Almost all clients required a written proposal from a prospective consultant.

- The written proposal from a prospective consultant had to specify goals and approach to the problem, time requirements, cost expectations and the experience of the consultant. They were evaluated along the same criteria.

- Proposals were evaluated in a variety of ways, some ranking them against others or an ideal, or by use of a matrix-grading approach, or by way of a verbal presentation or other informal discussions.

- Most clients gave feedback to consultants who were not selected, but only if asked for it.

- In evaluating a consultant's final report or finished project, most placed greatest emphasis on whether the outcome had been successful, but some placed importance on the consultant's frequency of interaction with the client, or formal written and verbal presentation.

- Most clients felt their own managers had the appropriate training or subject knowledge in order to pass 
judgment on the consultant's report or submitted work.

- Almost equally, consultants were either evaluated differently with higher standards than employees, or were treated the same as employees.

- Most felt that outside consultants could give more objective and valuable advice than insiders when it came to strategically or tactically complex issues.

- Most consultants were evaluated on a continuous basis as their work progressed.

- Most clients evaluated the work of a consultant as it was progressing by way of meetings between them, monitoring among other things, whether time-lines and milestones were met.

- In the large majority of cases, review of a consultant's work was considered to be objective and formal.

- Clients seemed to not be confident about how to assess the quality of information or work that the consultant provided to be sure it was helpful, and if not as to who would be responsible.

- Judging a consultant's work was done by looking at specific details as well as by an overall assessment.

- When assessing the quality of a consultant's work, in addition to the report, almost all clients tried to get feedback from other employees and managers.

- Most clients expected their consultants to guide them through their specific recommendations, teaching as they went.

- In very many instances clients tried to train employees within the firm to learn from the consultant, taking over their role, rendering the consultants unnecessary.

- In most cases the client expected the consultant to demonstrate how his/her findings related to the firm's strategy and tactics.

- As to implementing the findings, in most cases the client manager, the project team, or anyone affected made this decision, even shareholders, but not the consultant.

- Almost all clients felt comfortable stating that consultants delivered the kind of information needed to make proper decisions.

- More often than not, clients felt consultants' suggestions were good, but were not clear on how to implement them.

- Mostly, it depended on the project as to whether the consultant should stay with the project after the report was submitted, on through the implementation stage to its successful completion by the client.

- Most clients considered the consulting experience to be more successful if he/she helped in the implementation of their suggestions, rather than just leaving the client on their own at that stage.

- While initially considered to be important in their selection, very few clients actually required guarantees from a consultant with respect to conforming to cost and time constraints and none indicated that any steps were taken if these requirements were not met.

- In most instances, payment to a consultant was made in installments over stages of the project, but some were paid at the end.

- Most clients had on occasion, terminated a consultant's services prior to completion of the work.

- In most cases clients conducted a follow-up evaluation of the consultant's advice to see how well it was suited to and predicted the outcome of the situation, but in a large number of cases this was not done.

- Almost always, consultants were held responsible or liable, either legally, morally, or ethically for their recommendations, making them take ownership in their work, that they must provide satisfactory results, or prove their worth even after the work was completed. Some clients indicated this was difficult to accomplish.

- Most consultants followed up on their own after the fact, to insure their initiatives were working.

- Clients all indicated they were either generally or very satisfied with the use of consultants.

\subsection{Limitations and Future Research}

The findings of this study offer numerous leads for more extensive research that can be based on and related to this work. Some ideas follow. As previously noted, this study was done in the year 2000 as a qualitative, exploratory 
investigation of issues raised in the literature at that time. As such, it serves as a benchmark study to which current and future research can be compared. New inquiries might be based on up-dates in the literature and the formation of additional hypotheses based on these findings and new expectations. Quantitative statistical data obtained from the implementation of structured questionnaires would allow significance testing, a more detailed analysis and more definitive conclusions on a range of issues. To mention a few, these might deal with comparisons across consulting services, or those who use them, or an archival study to compare these results to those obtained in the future.

\section{References}

Anonymous. (1999). What do Healthcare Organizations Want from a Consultant? Health Management Technology, 20(2), 30-33.

Barnett, Dick. (1999). What to Look for in a TPA (Third-Party Administrator). Business \& Health, 17(2), 25-27.

Cohen, Andy. (1999). Are Consultants Worth It? Sales \& Marketing Management, 151(9), 32-42.

Commodity Code Directory: a comprehensive listing of products and services bought by the State of New Jersey. (1998). State of New Jersey, Department of the Treasury, Division of Purchase \& Property, Purchase Bureau, 29-30.

Dennis, Anita. (1999). Consulting to Lawyers and Families. Journal of Accountancy, 187(3), 68-71.

Everett, Jeannine Bergers. (1997). The Missing Link. Marketing Research: A Magazine of Management \& Applications, 9(1), 33-36.

Gallay, Ralph. (2013). Executive Guidelines for Selecting Consultants. International Journal of Business and Management, 8(8), 41-48. http://dx.doi.org/10.5539/ijbm.v8n8p41

Gallay, Ralph. (2013). How Executives Evaluate Consultants. World Academy of Researchers, Educators and Scholars in Business, Social Sciences, Humanities and Education (WARES), Conference Abstract Proceedings, 1(1), 53, July 2013, Cape Town, South Africa.

Lee, Hanjoon, Jay D. Lindquist, \& Frank Acito. (1997). Managers' Evaluation of Research Design and Its Impact on the Use of Research: An Experimental Approach. Journal of Business Research, 39(3), 231-240. http://dx.doi.org/10.1016/S0148-2963(96)00278-0

Messmer, Max. (1999). Getting the Most out of Consulting Arrangements. Strategic Finance, 81(3), 10-12.

Meyers, Herbert M., \& Murray J. Lubliner. (1998). Designing the Designer. Beverage World, 117(1664), 78-82.

Roberts, Bill. (1999). What Does it Take to Develop an HRIS (Human Resource Information Systems) Professional? HR Magazine, 44(2), 110-116.

Semon, Thomas T. (1997). Lots of Information, but How Much of It is Good? Marketing News, 31(10), 7. 